\title{
Associating liver partition and portal vein ligation for staged hepatectomy versus conventional two-stage hepatectomy: a systematic review and meta-analysis
}

\author{
Zheng Zhou ${ }^{\dagger}$, Mingxing $\mathrm{Xu}^{\dagger}$, Nan Lin, Chuzhi Pan, Boxuan Zhou, Yuesi Zhong and Ruiyun $\mathrm{Xu}^{*}$
}

\begin{abstract}
Background: It is generally accepted that an insufficient future liver remnant is a major limitation of large-scale hepatectomy for patients with primary hepatocellular carcinoma. Conventional two-stage hepatectomy (TSH) is commonly considered to accelerate future liver regeneration despite its low regeneration rate. Associating liver partition and portal vein ligation for staged hepatectomy (ALPPS), which is characterized by a rapid regeneration, has brought new opportunities.

Methods: Relevant studies were identified by searching the selected databases up to September 2017. Then, a meta-analysis of regeneration efficiency, complication rate, R0 resection ratio, and short-term outcomes was performed.

Results: Ten studies, comprising 719 patients, were included. The overall analysis showed that ALPPS was associated with a larger hyperplastic volume and a shorter time interval $(P<0.00001)$ than TSH. ALPPS also exhibited a higher completion rate for second-stage operations (odds ratio, OR 9.50; $P<0.0001$ ) and a slightly higher rate of R0 resection (OR 1.90; $P=0.11)$. Interestingly, there was no significant difference in 90-day mortality between the two treatments (OR 1.44; $P=0.35$ ).

Conclusions: These results indicate that compared with TSH, ALPPS possesses a stronger regenerative ability and better facilitates second-stage operations. However, the safety, patient outcomes, and patient selection for ALPPS require further study.
\end{abstract}

Keywords: ALPPS, Two-stage hepatectomy, Meta-analysis

\section{Background}

Multiple and large liver cancers remain a major challenge in liver surgery, although hepatectomy has become the most effective treatment [1]. A very common reason is the limited future liver remnant (FLR), one of the determining factors leading to postoperative liver failure (PLF), which restricts the application of this method. Commonly, a volume of over $20 \%$ FLR must remain to avoid PLF in a normal liver [2]. Conventional two-stage hepatectomy (TSH), including portal vein embolization

\footnotetext{
*Correspondence: drxruiyun@163.com

${ }^{\dagger}$ Equal contributors

Department of Hepatobiliary Surgery, Third Affiliated Hospital of Sun Yat-sen University, No. 600 Tianhe Road, Guangzhou, Guangdong, China
}

(PVE) or portal vein ligation (PVL) accompanied by subsequent hepatectomy, represents one solution to this dilemma [3]. Regrettably, the shortcomings of a long time interval and low regeneration efficiency seriously limit its application [4]. In 2012, a new surgical approach named "associating liver partition and portal vein ligation for staged hepatectomy (ALPPS)", characterized by great liver regeneration efficiency, was proposed by Schnitzbauer et al. [5]. However, standard methods for patient selection and the long-term outcomes of this new approach remain controversial.

Several systematic reviews have examined the advantages and disadvantages of ALPPS, especially the ability to promote an increased FLR. However, this method 


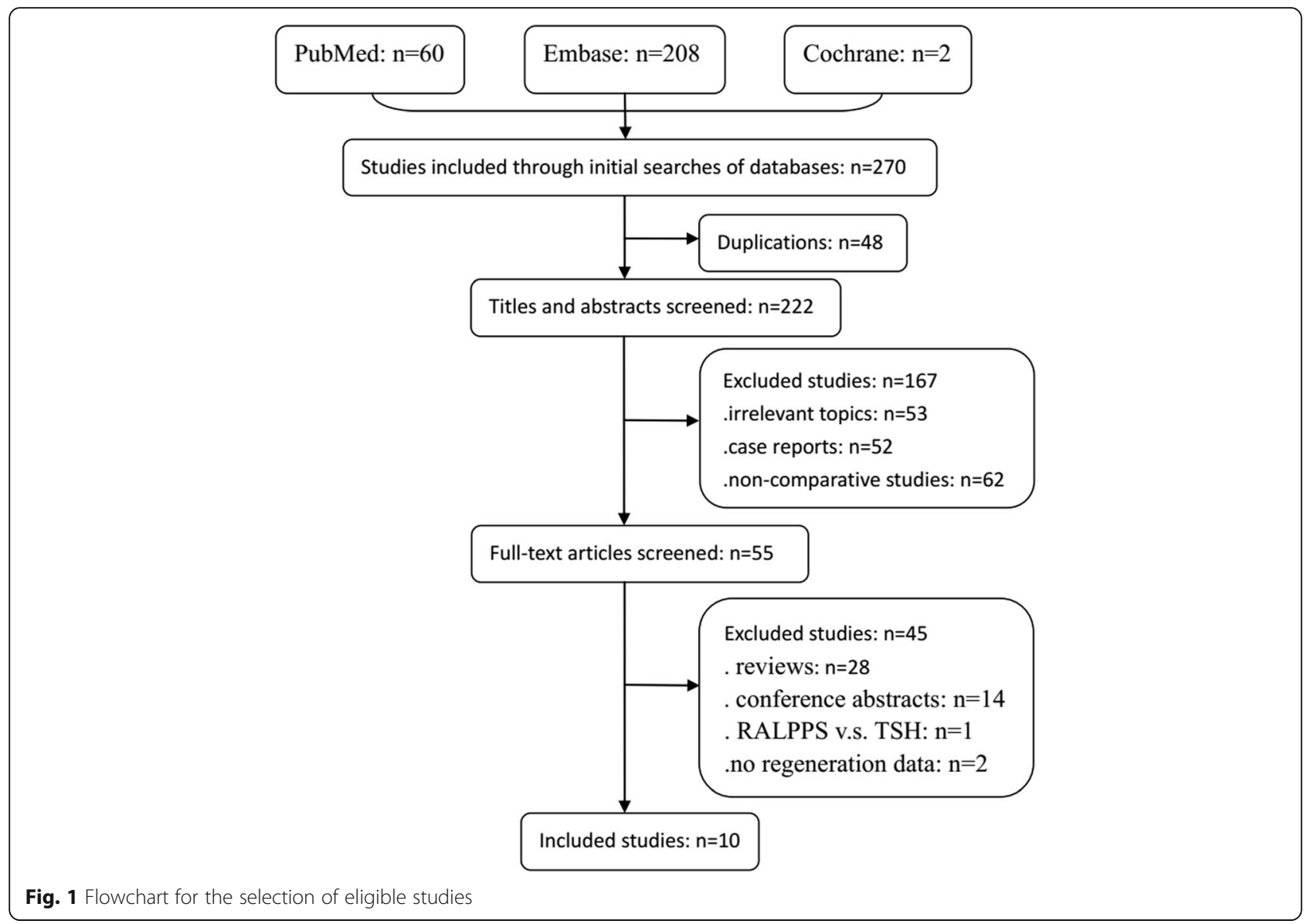

Table 1 Clinical and pathological characteristics of the included studies

\begin{tabular}{|c|c|c|c|c|c|c|c|c|c|}
\hline Author & Year & $\begin{array}{l}\text { No. of } \\
\text { patients }\end{array}$ & $\begin{array}{l}\text { Preoperative } \\
\text { chemotherapy }\end{array}$ & $\begin{array}{l}\text { Tumor } \\
\text { size }(\mathrm{mm})\end{array}$ & $\begin{array}{l}\text { TNM } \\
\text { stage }\end{array}$ & $\begin{array}{l}\text { Comparable } \\
\text { variables }\end{array}$ & Level & $\begin{array}{l}\text { Study } \\
\text { design }\end{array}$ & $\begin{array}{l}\text { Quality } \\
\text { score }\end{array}$ \\
\hline Knoefel et al. [14] & 2012 & $\begin{array}{l}\text { ALPPS(7) } \\
\text { PVE(15) }\end{array}$ & $\begin{array}{l}5 \\
\mathrm{NI}\end{array}$ & $\mathrm{Nl}$ & $\mathrm{Nl}$ & $1,3,7$ & 4 & RCS & 6 \\
\hline Shindoh et al. [19] & 2013 & $\begin{array}{l}\text { ALPPS(25) } \\
\text { PVE(144) }\end{array}$ & $\begin{array}{l}12 \\
94\end{array}$ & $\mathrm{NI}$ & $\mathrm{Nl}$ & $1,2,5,7$ & 3 & $\mathrm{RCS}$ & 7 \\
\hline Croome et al. [13] & 2014 & $\begin{array}{l}\text { ALPPS(15) } \\
\text { PVE(53) }\end{array}$ & $\begin{array}{l}14 \\
40\end{array}$ & $\mathrm{NI}$ & $\mathrm{Nl}$ & $1,2,5,7,9$ & 3 & RCS & 8 \\
\hline Schadde et al. [18] & 2014 & $\begin{array}{l}\text { ALPPS(48) } \\
\text { PVE/PVL(83) }\end{array}$ & $\begin{array}{l}28 \\
44\end{array}$ & $\mathrm{Nl}$ & $\mathrm{NI}$ & $1,2,4,5,7,8,9$ & 3 & RCS & 9 \\
\hline Ratti et al. [16] & 2015 & $\begin{array}{l}\text { ALPPS(12) } \\
\text { PVE/PVL(36) }\end{array}$ & $\begin{array}{l}9 \\
30\end{array}$ & $\mathrm{Nl}$ & $\mathrm{NI}$ & $1,2,5,6,7,8,9$ & 3 & $\mathrm{RCS}$ & 9 \\
\hline Matsuo et al. [15] & 2015 & $\begin{array}{l}\text { ALPPS(8) } \\
\text { PVE(14) }\end{array}$ & $\begin{array}{l}8 \\
12\end{array}$ & $\begin{array}{l}21 \\
35.5\end{array}$ & $\mathrm{Nl}$ & $1,2,3,5,7$ & 4 & RCS & 6 \\
\hline Tanaka et al. [20] & 2015 & $\begin{array}{l}\text { ALPPS(11) } \\
\text { PVE/PVL(54) }\end{array}$ & $\begin{array}{l}11 \\
47\end{array}$ & $\begin{array}{l}22 \\
40.5\end{array}$ & $\mathrm{NI}$ & $1,2,7$ & 4 & RCS & 7 \\
\hline Adam et al. [11] & 2016 & $\begin{array}{l}\text { ALPPS(17) } \\
\text { PVE/PVL(41) }\end{array}$ & $\begin{array}{l}17 \\
41\end{array}$ & $\begin{array}{l}40 \\
50\end{array}$ & $\mathrm{NI}$ & $1,2,5,6,7,8$ & 4 & RCS & 7 \\
\hline Chia et al. [12] & 2017 & $\begin{array}{l}\text { ALPPS(10) } \\
\text { PVE/PVL(29) }\end{array}$ & $\begin{array}{l}3 \\
16\end{array}$ & $\begin{array}{l}81 \\
66\end{array}$ & $\mathrm{NI}$ & $1,2,4,5,7$ & 4 & RCS & 7 \\
\hline Sandström et al. [17] & 2017 & $\begin{array}{l}\text { ALPPS(48) } \\
\text { PVE/PVL(49) }\end{array}$ & $\begin{array}{l}\mathrm{Nl} \\
\mathrm{NI}\end{array}$ & $\begin{array}{l}54 \\
49\end{array}$ & $\mathrm{NI}$ & $1,2,3,5,7,8,9$ & 1 & $\mathrm{RCT}$ & 8 \\
\hline
\end{tabular}

1: age; 2: preoperative chemotherapy; 3: preoperative liver function; 4: pathology state before operation; 5: pathology type of tumor; 6: pathology stage; 7: sex; 8: ASA score; 9: BMI

$N I$ no information, $R C S$ retrospective cohort study, $R C T$ randomized controlled trial 


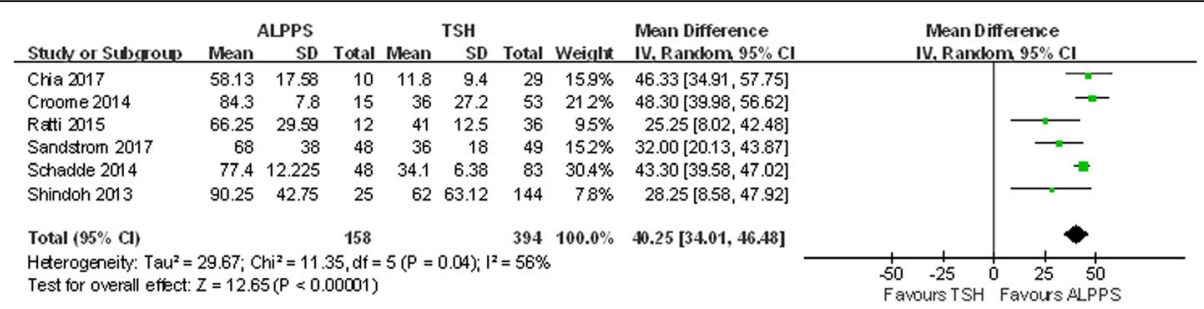

Fig. 2 Forest plot and meta-analysis of the absolute value of future liver remnant regeneration

continues to provoke heated debate because of its high mortality and unclear feasibility compared with other technologies, such as conventional TSH. Moreover, patient outcomes of ALPPS also remain uncertain [6-8]. In the current analysis, we systematically searched for published studies comparing ALPPS and TSH to evaluate the liver regeneration efficiency, safety, and complication rates of these two methods.

\section{Methods}

The prospective agreement on study objectives, literature search methods, inclusion and exclusion criteria, outcome measurements, and statistical analysis methods were selected according to the Preferred Items for Systematic Reviews and Meta-Analysis (PRISMA) (Additional file 1: Appendix S1) and Meta-Analysis of Observational Studies in Epidemiology (MOOSE) guidelines (Additional file 2: Table S1).

There is currently no agreement on the definition of TSH. For the purpose of statistical analysis, the TSH group included patients who received PVE, PVL, or both.

\section{Search strategy and selection criteria}

A search of the PubMed, Embase, and Cochrane Library databases was performed to identify all studies comparing ALPPS and TSH. The following terms were searched: "liver partition," "liver transection," "portal vein occlusion," "PVO," "portal vein embolization," "PVE," "portal vein ligation," "PVL," "associating liver partition and portal vein ligation for staged hepatectomy,", "ALPPS," "staged hepatectomy," and "two-stage hepatectomy." The publication time was from January 1, 2009, to September 30, 2017, and the language was restricted to English.

All comparative studies comparing ALPPS with TSH in primary or secondary liver tumor patients who received surgery for staged hepatectomy were included. These studies included at least one quantitative outcome of interest, such as regeneration efficiency, time interval of the two stages, completion rate for second-stage operations, tumor deterioration, insufficient regeneration, R0 resection ratio, liver failure, bile leak, 90-day mortality, and 1-year disease-free survival. The excluded studies were those with irrelevant topics, case reports, noncomparative studies, review articles, letters, incomplete multiple published reports, and conference abstracts.

\section{Data extraction and outcomes of interest}

Two authors independently extracted and summarized the following data: patient characteristics, research designs, inclusion and exclusion criteria, and reported outcomes. Any disagreements were jointly resolved by the authors.

\section{Quality assessment and statistical analysis}

The studies ultimately included were classified according to the "2011 Levels of Evidence for Common Harms (Treatment Harms)" (Centre for Evidence Based Medicine, Oxford, UK). These levels of evidence can be described as follows: systematic reviews of randomized trials, systematic reviews of nested casecontrol studies and n-of-1 trials (level 1); individual randomized trials or (exceptionally) observational studies

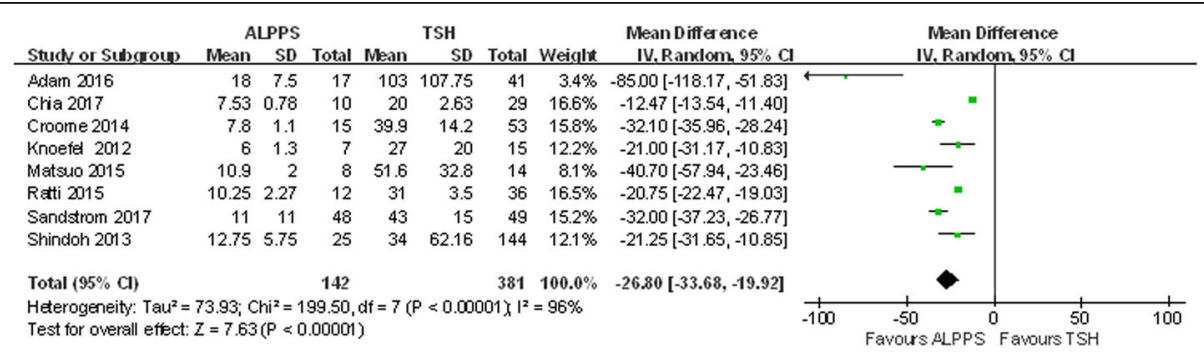

Fig. 3 Forest plot and meta-analysis of the time interval between the two stages 


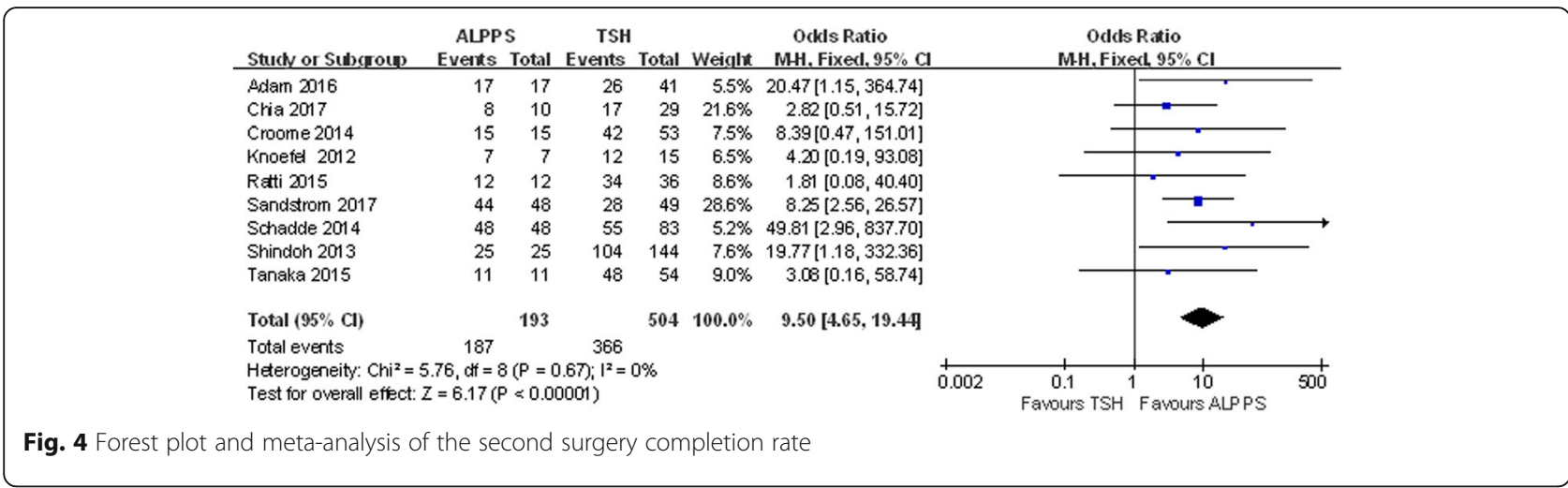

with a dramatic effect (level 2); non-randomized controlled cohort/follow-up studies, provided there are sufficient numbers to rule out a common harm (level $3)$; case-series, case-control studies, or historically controlled studies (level 4); and mechanism-based reasoning (level 5) [9].

The weighted mean difference (WMD) and OR were used to compare continuous and dichotomous variables, respectively. The OR and 95\% confidence interval (CI) were calculated for binary data. $P$ values $<0.05$ were considered to indicate statistical significance. When the mean and variance were not reported, they were calculated using the median and range through a formula reported by Hozo SP [10]. Heterogeneity between studies was assessed using the chi-squared test and $I^{2}$. A $P$ value $<0.10$ was used to indicate heterogeneity. Fixed-effect models were used for cumulative analyses when there was a lack of heterogeneity; otherwise, random-effect models were used.

The quality of all included studies was assessed using the Newcastle-Ottawa Scale (NOS) system, and patient selection, study comparability, and outcomes were evaluated. Scores ranging from 0 to 9 were calculated for each included study, and studies achieving a score of 6 or more were considered to be of good quality. Statistical analysis was performed using Review Manager Version 5.2 software (Cochrane Collaboration, Oxford, UK) (Additional file 3: Table S2).

\section{Results}

Figure 1 shows the results of the search strategy and all studies that were included and excluded. In total, 270 studies were identified from the databases. Fortyeight studies were excluded because of duplication, and 167 studies were excluded after the titles and abstracts had been reviewed. The full-text articles of 55 studies were screened in detail. Of these articles, 28 reviews were excluded, 14 conference abstracts were excluded, and 1 study comparing radiofrequencyALPPS (RALPPS) and TSH was excluded. Another 2 studies were excluded due to the lack of regeneration data. Between the two reviewers, there was 95\% agreement for study selection and $96 \%$ agreement for quality assessment of the trials.

\section{Characteristics and quality of the included studies}

Ten studies were included according to the inclusion criteria [11-20]. Table 1 shows the clinical characteristics of these studies. Nine of the studies were retrospective articles, and only one randomized controlled trial (RCT) was identified. The references of these included studies indicated that no other studies existed with which to assess the topic further. In total, 201 patients in the ALPPS group and 518 patients in the TSH group were analyzed in this meta-analysis. Six studies compared ALPPS with PVE/PVL, and 4 studies compared ALPPS

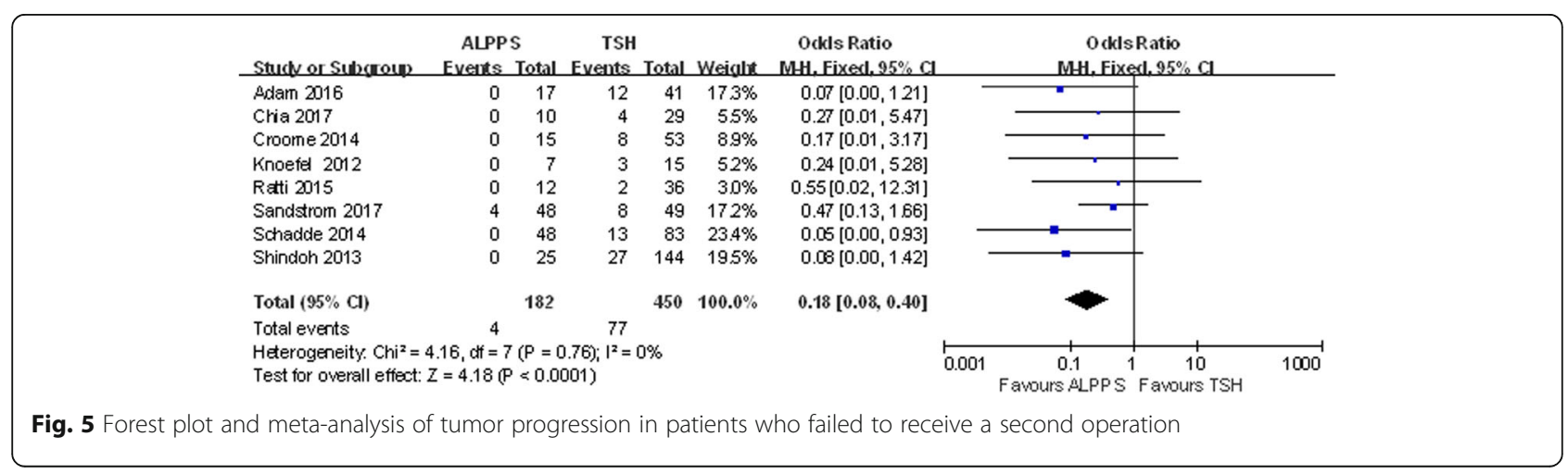




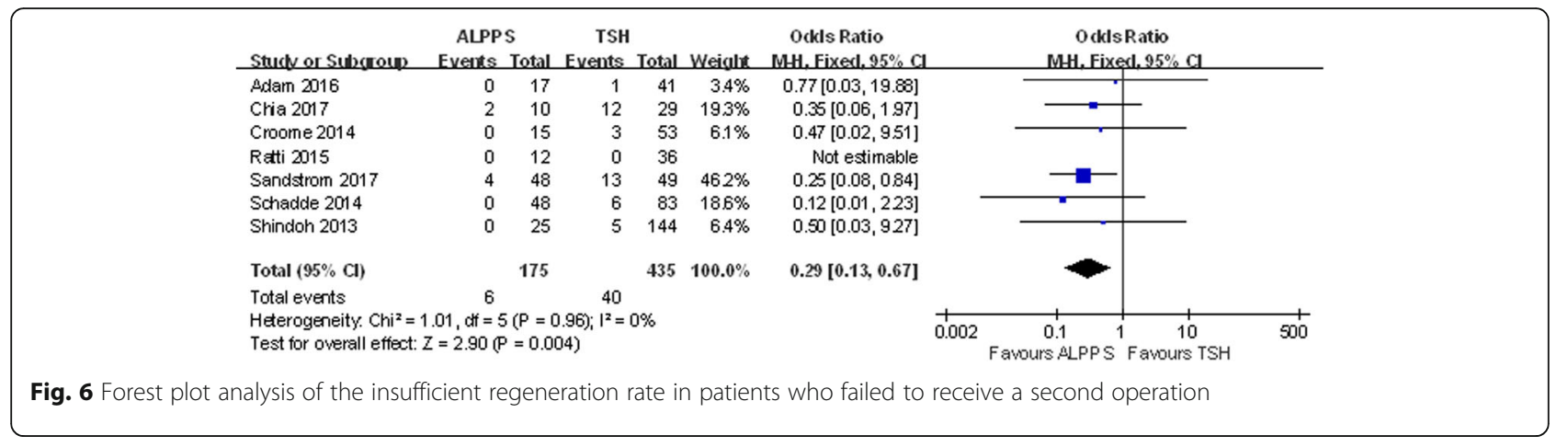

with PVE only. Two studies comprised a possible overlapping population, but they were both included because they investigated different outcomes $[15,20]$. Complete shortterm follow-up data were available in two studies. The preoperative chemotherapy rate was $48-100 \%$ in the ALPPS group and $53-87 \%$ in the TSH group.

\section{FLR regeneration}

Figure 2 summarizes the absolute value of FLR regeneration in the 6 included studies. The results of the random-effect model indicated that ALPPS led to greater regeneration than TSH did (WMD 40.25; 95\% CI, 34.01 46.48; $P<0.00001)$.

\section{Time interval of the two stages}

Eight studies were included in this section, and the results are shown in Fig. 3. The duration before the second-stage operation was shorter for ALPPS than for TSH (WMD 26.80; 95\% CI,- 33.68 - 19.92; $P<0.00001)$; however, significant heterogeneity was observed (chi-square $=199.50$; $\left.\mathrm{df}=7 ; P<0.00001 ; I^{2}=96 \%\right)$.

\section{Completion rate of second-stage operations}

Nine studies included information on the completion rate for second-stage operations. There was no apparent heterogeneity in these studies (chi-square $=5.76$; $\mathrm{df}=8$; $P=0.67 ; I^{2}=0 \%$ ). The completion rate of second-stage operations was $96.89 \%$ in ALPPS and $72.62 \%$ in TSH when analyzed with a fixed model (OR 9.50; 95\% CI,
4.65 19.44; $P<0.00001$ ) (Fig. 4), and this difference was statistically significant.

The reasons for failure to complete the staged operations included tumor progression and insufficient FLR. Eight studies were included, and only $2 \%$ of patients experienced tumor progression before the second operation in ALPPS, lower than the $17.1 \%$ in TSH. (OR 0.18; 95\% CI, 0.08 0.40; $P<0.0001$ ) (Fig. 5). The difference in the insufficient regeneration rate between ALPPS and TSH was also significant, with TSH showing a higher rate than ALPPS (OR 0.29; 95\% CI, $0.13 \sim 0.67 ; P=0.0004$ ) (Fig. 6).

\section{Postoperative complications}

The incidence of postoperative complications was higher in the ALPPS group after two stages, yet no significant differences were observed (Figs. 7 and 8). Eight studies included PLF data. In the ALPPS group, $9.80 \%$ of patients experienced liver failure, and this percentage was lower than the $13.96 \%$ observed in the TSH group, although this difference was not significant (OR 0.86; 95\% CI, 0.46 1.64; $P=0.66$ ) (Fig. 9). Another 5 studies mentioned postoperative bile leaks. In these studies, we observed a higher bile leak rate after the stage 2 operation in the ALPPS group (OR 2.28; 95\% CI, 1.21 4.26; $P=0.009$ ) (Fig. 10), and a similar conclusion could be drawn after stage 1, although the difference was not significant (OR 1.74; 95\% CI, 0.42 7.20; $P=0.44$ ) (Fig. 11).

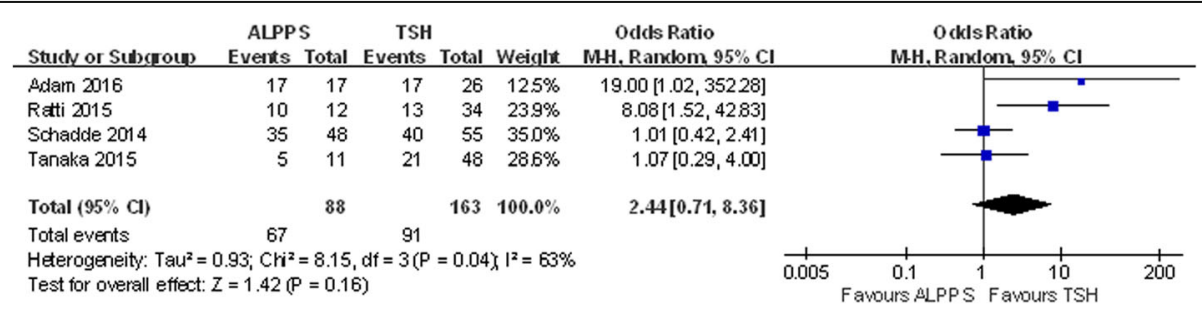

Fig. 7 Forest plot analysis of postoperative complications in patients after stage 2 operation 


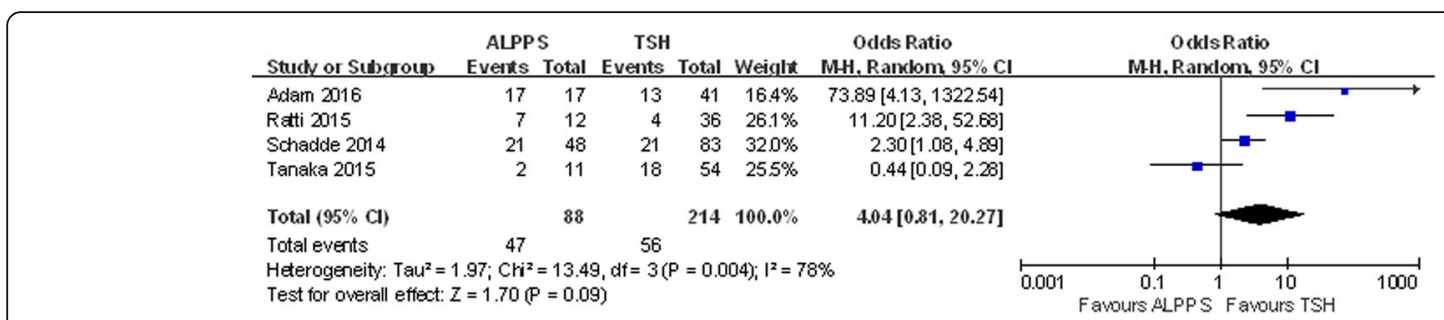

Fig. 8 Forest plot analysis of postoperative complications in patients after stage 1 operation

\section{R0 resection and 1-year disease-free survival}

Four studies included data on R0 resection and 1-year disease-free survival, and no heterogeneity was observed in these studies (chi-square $=2.51 ; \mathrm{df}=2 ; P=$ $\left.0.29 ; I^{2}=20 \%\right)$. The results showed that in the ALPPS group, $78.51 \%$ of patients obtained R0 resection, which was slightly higher than the $73.94 \%$ in the TSH group, although the difference was not statistically significant (OR 1.90; 95\% CI, 0.87 4.19; $P=0.11$ ) (Fig. 12). Additionally, ALPPS showed a lower 1-year disease-free survival rate than TSH did (OR 0.33; 95\% CI, 0.16 0.70; $P=0.004)$ (Fig. 13).

\section{Short-term outcomes}

There were 7 studies related to this topic, and no heterogeneity between studies was identified (chi-square $=$ 3.15 ; $\mathrm{df}=6 ; P=0.79 ; I^{2}=0 \%$ ). Although the 90 -day mortality was higher for patients receiving ALPPS (OR 1.44; $95 \% \mathrm{CI}, 0.67 \sim 3.08)$, this difference was not statistically significant $(P=0.35)$ (Fig. 14).

\section{Discussion}

This systematic review and meta-analysis included 719 patients and aimed to compare the regeneration efficiency, safety, and complication rates of ALPPS and TSH. The absolute value of FLR regeneration in ALPPS was significantly higher than that in TSH, and the interval of the two stages in ALPPS was clearly shorter than that in TSH. In addition, ALPPS was associated with a higher completion rate, a lower probability of tumor progression during the stage interval, and a lower insufficient regeneration rate; these findings are similar to those of previous studies [21-23]. However, complications, especially bile fistulas, were much more frequent in ALPPS, likely because of the liver splitting required in this procedure. Although ALPPS was associated with a lower rate of 1-year disease-free survival, there was no significant difference in the 90-day mortality rate between these two methods.

Given the safety of operation and possibility of PLF, a surgeon's decision regarding a secondary ALPPS surgery is often affected by various factors. Two common factors are residual liver volume and function. In general, once the volume of liver regeneration reaches $20 \%$ of the normal liver and $30 \%$ of the cirrhotic liver, secondary surgery can be safely performed [13-16, 18-20]. The rate of FLR regeneration differs during the regeneration progress. For instance, Correa reported that for 10 patients who did not accept resection but received PVE, the FLR regeneration rate was different at various periods within the 1-year follow-up, and the liver continued to grow even 1 year after PVE [24]. However, the FLR regeneration volume alone still cannot reflect effective liver regeneration since patients usually have different regeneration rates after the operation. In our study, the absolute value of FLR regeneration was higher in ALPPS than in TSH, similar to the findings of previous studies. However, there was no uniform calculation of kinetic growth rate (KGR), and we did not perform a unified analysis of these included studies to better assess liver regeneration.

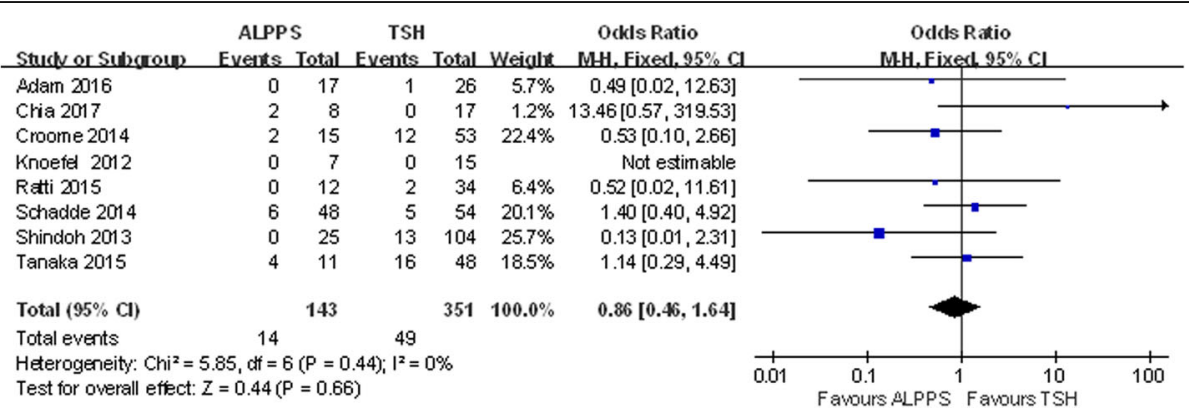

Fig. 9 Forest plot and meta-analysis of the postoperative liver failure rate in patients after stage 2 operation 


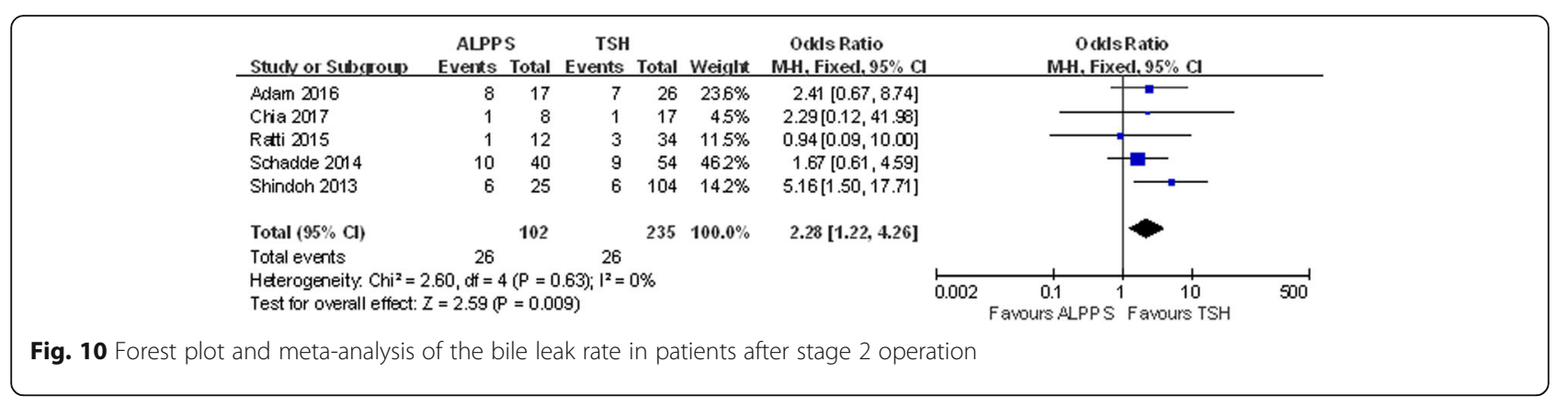

Furthermore, the pathological state of the liver also influences the potential for regeneration. Commonly, insufficient regeneration is accompanied by chronic liver disease. Chia et al. reported that patients with hepatitis $B$ virus (HBV)-related cirrhosis require a longer time for regeneration before stage 2 [25]. Furthermore, neoadjuvant chemotherapy and chemotherapy have been reported to inhibit liver regeneration to some extent.

What is the best way to evaluate liver regeneration? In 2013, Shindoh et al. proposed the concept of KGR to try to resolve this issue [26]. However, KGR may reflect only the increased volume, not the increased function of the liver. Moreover, there is no uniform calculation for KGR, and therefore, this index remains controversial. Additionally, several studies have shown that many cytokines expressed during the liver regeneration process following ALPPS are associated with regeneration [27-29]. Portal hemodynamics and immature hepatocytes during the process were both considered influencing factors $[15,21$, 30, 31]. Given all these factors, the most effective method to evaluate the function of the FLR remains unclear and further work is necessary to address the timing and selection of optimal candidates for staged hepatectomy.

Additionally, the interval time in TSH was longer, and tumor progression was more common [32]. It is possible that the long time interval of TSH caused a higher risk of tumor progression. Only 4 patients were diagnosed with tumor progression in the ALPPS group in this study. Moreover, Fukami reported that Ki-67, a marker of cell proliferation, was increased to $80 \%$ in tumor cells after the second stage of ALPPS, and this increase was higher than that identified in the first stage in patients with colon cancers and synchronous multiple liver metastases [33]. However, there is no consensus regarding whether the rapid regeneration response in ALPPS can aggravate the progression of the primary tumor. In addition, some researchers have reported that the incidence of postoperative tumor recurrence ranges from 14 to $87 \%$, which is higher than that of TSH. Our study also indicated a similar conclusion. Furthermore, a higher R0 ratio could be seen in the ALPPS group; this result may be related to the entire splitting of stage 1. Additionally, there is no benefit to extending the interval time before stage 2, as a decreased KGR may occur at the seventh day after stage 1 [34]. At the same time, considering that performing the stage 2 operation without sufficient preoperative assessment of the liver regeneration may easily lead to liver failure, it is necessary to establish an evaluation standard for assessing liver function after stage 1 .

The mortality and complication rate are believed to be higher following ALPPS than following TSH. Our results also showed this trend although there was no significant difference between the two groups. Commonly increased portal blood, the most distinctive characteristic differentiating ALPPS from TSH, would lead to portal hyperperfusion which can conversely cause liver failure. Allard et al.'s research has shown a positive correlation between the portal vein pressure (PVP) and 90-day mortality. A multivariate analysis also indicated that PVP after hepatectomy was an independent predictor for PLF [35]. Thus, the hemodynamic change in the portal vein after hepatectomy is closely related to patient prognosis. The increased portal vein flow in ALPPS can block the circulation from two parts of the liver and result in centralized hepatic blood flow, which ultimately leads to portal hyperperfusion of the FLR [36]. However, with the hepatic

\begin{tabular}{|c|c|c|c|c|c|c|c|c|c|}
\hline Stucke or Subcreup & $\begin{array}{l}\text { ALPP } \\
\text { Events }\end{array}$ & Iotal & $\begin{array}{l}\text { TSH } \\
\text { Events }\end{array}$ & Iotal & Weiglt & $\begin{array}{c}\text { Ockls Ratio } \\
\text { MH,Fixed. } 25 \% \mathrm{Cl}\end{array}$ & & $\begin{array}{c}\text { Odkls Ratio } \\
\text { MH. Fixed. } 95 \% \mathrm{Cl}\end{array}$ & \\
\hline Adam 2016 & 2 & 17 & 1 & 41 & $19.1 \%$ & $5.33[0.45,63.22]$ & & 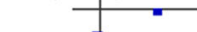 & \\
\hline Ratti 2015 & 0 & 12 & 1 & 36 & $278 \%$ & $0.95[0.04,24.78]$ & & & \\
\hline Schadde 2014 & 1 & 48 & 2 & 83 & $53.1 \%$ & $0.86[0.08,9.76]$ & & & \\
\hline Total $(95 \% \mathrm{Cl})$ & & 77 & & 160 & $100.0 \%$ & $1.74[0.42,7.20]$ & & & \\
\hline Total events & 3 & & 4 & & & & & & \\
\hline \multicolumn{6}{|c|}{$\begin{array}{l}\text { Heterogeneity. } \mathrm{Chi}^{2}=1.24 \text {, df }=2(P=0.54) ;\left.\right|^{2}=0 \% \\
\text { Test for overall effect: } Z=0.77(P=0.44)\end{array}$} & & 0.005 & $\begin{array}{ccc}0.1 & 1 & 10 \\
\text { urs BLPPS } & \text { F awours TS }\end{array}$ & 200 \\
\hline
\end{tabular}

Fig. 11 Forest plot and meta-analysis of the bile leak rate in patients after stage 1 operation 


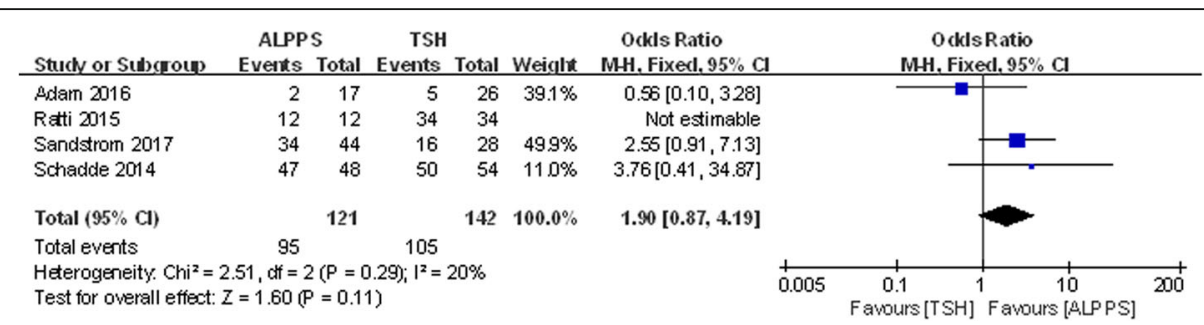

Fig. 12 Forest plot and meta-analysis of the R0 resection ratio

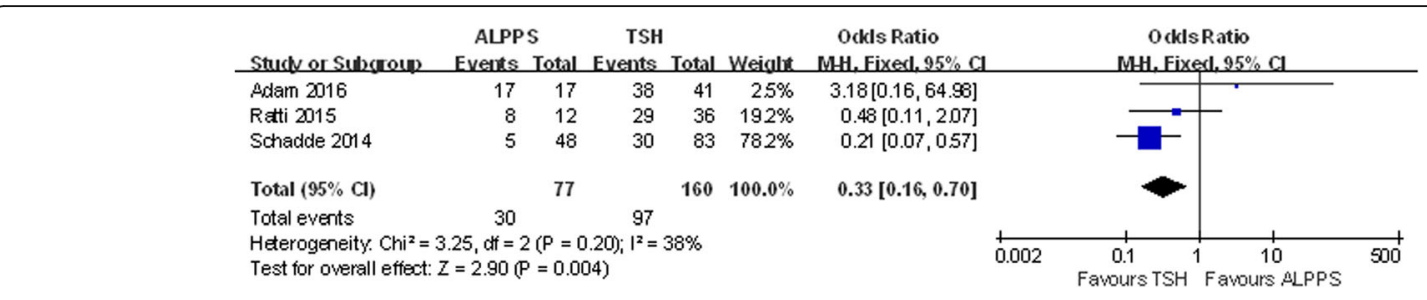

Fig. 13 Forest plot and meta-analysis of 1-year disease-free survival

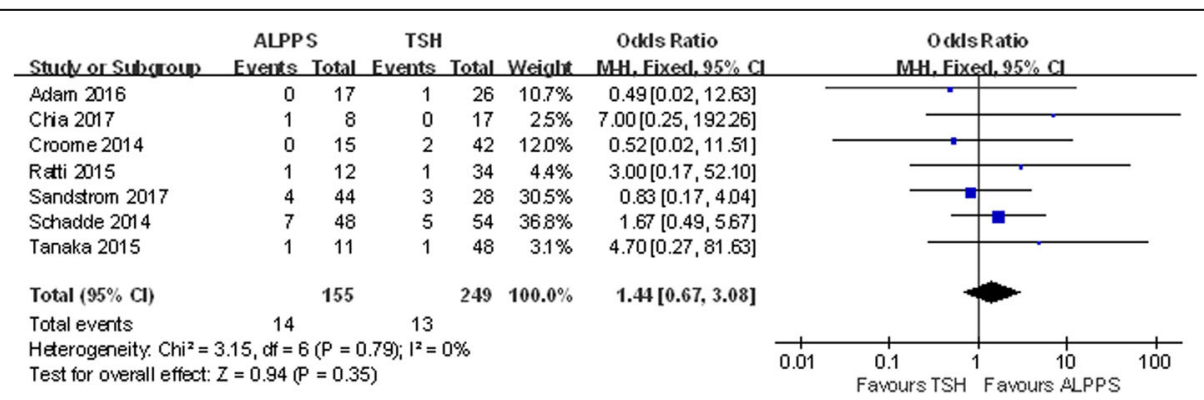

Fig. 14 Forest plot and meta-analysis of 90-day mortality after stage 2 operation 
artery buffering effect, the arterial flow in the non-ligated portion decreases to partly adapt to the increased portal vein flow [37]. Vicente et al. investigated the pathological specimens of small-size syndrome patients and found that sinusoidal dilatation of the tissue was directly related to liver failure [38].

There are many limitations of this meta-analysis. First, most of the included studies presented a low level of evidence, ranging from level 3 to level 4 . Second, there was significant heterogeneity in some of the results because of the differences across studies in institutions, numbers of patients, types of primary tumors, and other factors. Third, there was obvious publication bias among some of the included studies.

\section{Conclusions}

In conclusion, this meta-analysis found that ALPPS was associated with a higher regeneration efficiency and a higher operation completion rate than TSH. Patients receiving TSH were more likely to experience tumor progression during the time interval. ALPPS also provided a higher rate of $\mathrm{R} 0$ resection, although the rate of complications after stage 2 was higher than that of TSH. However, the long-term outcome of ALPPS remains unclear, and additional studies are needed to address this issue.

\section{Additional files}

Additional file 1: Appendix S1. PRISMA 2009 Checklist. (DOC 64 kb)

Additional file 2: Table S1. MOOSE Checklist. (DOCX $21 \mathrm{~kb}$ )

Additional file 3: Table S2. Assessment of quality. (DOCX $15 \mathrm{~kb}$ )

\section{Abbreviations}

ALPPS: Associating liver partition and portal vein ligation for staged hepatectomy; Cl: Confidence interval; FLR: Future liver remnant; KGR: Kinetic growth rate; NOS: Newcastle-Ottawa Scale; OR: Odds ratio; PLF: Postoperative liver failure; PVE: Portal vein embolization; PVL: Portal vein ligation;

PVO: Portal vein occlusion; PVP: Portal vein pressure;

RALPPS: Radiofrequency-ALPPS; TSH: Two-stage hepatectomy;

WMD: Weighted mean difference

\section{Acknowledgements}

None.

\section{Funding}

This work was supported by the Natural Science Foundation of Guangdong Province, China (2014A030313067 and 2014A030313144).

\section{Availability of data and materials}

All data generated or analyzed during this study are included in this published article.

\section{Authors' contributions}

RYX and ZZ designed the study; ZZ and MXX collected the data; NL and YSZ performed the statistical analysis; ZZ and MXX drafted the manuscript; CZP and $B X Z$ revised and proofread the manuscript. All authors read and approved the final manuscript.

\section{Ethics approval and consent to participate}

All patients in this study provided informed consent before undergoing hepatectomy. All procedures in this study were performed in accordance with the principles of the Research Ethics Committee of the Third Affiliated Hospital of Sun Yat-Sen University and with the 1964 Helsinki Declaration and its amendments.

\section{Consent for publication}

Not applicable.

\section{Competing interests}

The authors declare that they have no competing interests.

\section{Publisher's note}

Springer Nature remains neutral with regard to jurisdictional claims in published maps and institutional affiliations.

Received: 2 October 2017 Accepted: 8 December 2017

Published online: 19 December 2017

\section{References}

1. Agrawal S, Belghiti J. Oncologic resection for malignant tumors of the liver. Ann Surg. 2011;253:656-65.

2. Clavien PA, Petrowsky H, DeOliveira ML, Graf R. Strategies for safer liver surgery and partial liver transplantation. N Engl J Med. 2007;356:1545-59.

3. Jaeck D, Oussoultzoglou E, Rosso E, Greget M, Weber JC, Bachellier P. A twostage hepatectomy procedure combined with portal vein embolization to achieve curative resection for initially unresectable multiple and bilobar colorectal liver metastases. Ann Surg. 2004;240:1037-49. discussion 1049-1051

4. Abulkhir A, Limongelli P, Healey AJ, Damrah O, Tait P, Jackson J, Habib N, Jiao LR. Preoperative portal vein embolization for major liver resection: a meta-analysis. Ann Surg. 2008;247:49-57.

5. Schnitzbauer AA, Lang SA, Goessmann H, Nadalin S, Baumgart J, Farkas SA, Fichtner-Feigl S, Lorf T, Goralcyk A, Hörbelt R. Right portal vein ligation combined with in situ splitting induces rapid left lateral liver lobe hypertrophy enabling 2-staged extended right hepatic resection in smallfor-size settings. Ann Surg. 2012;255:405.

6. Vivarelli M, Vincenzi P, Montalti R, Fava G, Tavio M, Coletta M, Vecchi A, Nicolini D, Agostini A, Ahmed EA, et al. ALPPS procedure for extended liver resections: a single centre experience and a systematic review. PLoS One. 2015;10:e0144019.

7. Edmondson MJ, Sodergren MH, Pucher PH, Darzi A, Li J, Petrowsky H, Campos RR, Serrablo A, Jiao LR. Variations and adaptations of associated liver partition and portal vein ligation for staged hepatectomy (ALPPS): many routes to the summit. Surgery. 2016;159:1058-72.

8. Cai YL, Song PP, Tang W, Cheng NS. An updated systematic review of the evolution of ALPPS and evaluation of its advantages and disadvantages in accordance with current evidence. Medicine (Baltimore). 2016;95:e3941.

9. Hidding JT, Beurskens CHG, Wees PJVD, Laarhoven HWMV, Sanden NVD: Oxford Centre for Evidence-Based Medicine, 2011 levels of evidence for common harms (treatment harms). 2014.

10. Hozo SP, Djulbegovic B, Hozo I. Estimating the mean and variance from the median, range, and the size of a sample. BMC Med Res Methodol. 2005;5:13.

11. Adam R, Imai K, Castro Benitez C, Allard MA, Vibert E, Sa Cunha A, Cherqui D, Baba H, Castaing D. Outcome after associating liver partition and portal vein ligation for staged hepatectomy and conventional two-stage hepatectomy for colorectal liver metastases. Br J Surg. 2016;103:1521.

12. Chia D, Yeo Z, Loh S, lyer SG, Bonney GK, Madhavan K, Kow A. Greater hypertrophy can be achieved with associating liver partition with portal vein ligation for staged hepatectomy compared to conventional staged hepatectomy, but with a higher price to pay? American Journal of Surgery. 2017:

13. Croome KP, Hernandez-Alejandro R, Parker M, Heimbach J, Rosen C, Nagorney DM. Is the liver kinetic growth rate in ALPPS unprecedented when compared with PVE and living donor liver transplant? A multicentre analysis. HPB. 2015;17:477-84.

14. Knoefel WT, Gabor I, Rehders A, Alexander A, Krausch M, Esch JSA, Fürst G, Topp SA. In situ liver transection with portal vein ligation for rapid growth of the future liver remnant in two-stage liver resection. Br J Surg. 2013;100:388-94.

15. Matsuo K, Murakami T, Kawaguchi D, Hiroshima Y, Koda K, Yamazaki K, Ishida Y, Tanaka K. Histologic features after surgery associating liver partition and portal vein ligation for staged hepatectomy versus those after hepatectomy with portal vein embolization. Surgery. 2016;159:1289. 
16. Ratti F, Schadde E, Masetti M, Massani M, Zanello M, Serenari M, Cipriani F, Bonariol L, Bassi N, Aldrighetti L. Strategies to increase the resectability of patients with colorectal liver metastases: a multi-center case-match analysis of ALPPS and conventional two-stage hepatectomy. Ann Surg Oncol. 2015; 22:1933-42.

17. Sandström P, Røsok BI, Sparrelid E, Larsen PN, Larsson AL, Lindell G, Schultz NA, Bjørnbeth BA, Isaksson B, Rizell M. ALPPS improves resectability compared with conventional two-stage hepatectomy in patients with advanced colorectal liver metastasis: results from a Scandinavian multicenter randomized controlled trial (LIGRO trial). Ann Surg. 2017; doi:10.1097/SLA.0000000000002511.

18. Schadde E, Ardiles V, Slankamenac K, Tschuor C, Sergeant G, Amacker N, Baumgart J, Croome K, Hernandez-Alejandro R, Lang H. ALPPS offers a better chance of complete resection in patients with primarily unresectable liver tumors compared with conventional-staged hepatectomies: results of a multicenter analysis. World J Surg. 2014;38:1510.

19. Shindoh J, Vauthey JN, Zimmitti G, Curley SA, Huang SY, Mahvash A, Gupta S, Wallace MJ, Aloia TA. Analysis of the efficacy of portal vein embolization for patients with extensive liver malignancy and very low future liver remnant volume, including a comparison with the associating liver partition with portal vein ligation for staged hepatectomy approach. J Am Coll Surg. 2013;217:126-33. discussion 133-124

20. Tanaka K, Matsuo K, Murakami T, Kawaguchi D, Hiroshima Y, Koda K, Endo I, Ichikawa Y, Taguri M, Tanabe M. Associating liver partition and portal vein ligation for staged hepatectomy (ALPPS): short-term outcome, functional changes in the future liver remnant, and tumor growth activity. European Journal of Surgical Oncology the Journal of the European Society of Surgical Oncology \& the British Association of Surgical Oncology. 2015;41:506.

21. Bertens KA, Hawel J, Lung K, Buac S, Pineda-Solis K, Hernandez-Alejandro R. ALPPS: challenging the concept of unresectability - a systematic review. Int J Surg. 2014;13:280.

22. Schadde E, Schnitzbauer AA, Tschuor C, Raptis DA, Bechstein WO, Clavien PA. Systematic review and meta-analysis of feasibility, safety, and efficacy of a novel procedure: associating liver partition and portal vein ligation for staged hepatectomy. Ann Surg Oncol. 2015;22:3109-20.

23. Zhang GQ, Zhang ZW, Lau WY, Chen XP. Associating liver partition and portal vein ligation for staged hepatectomy (ALPPS): a new strategy to increase resectability in liver surgery. Int J Surg. 2014;12:437-41.

24. Liu W, Zhou JG, Sun Y, Zhang L, Xing BC. Hepatic resection improved the long-term survival of patients with BCLC stage B hepatocellular carcinoma in Asia: a systematic review and meta-analysis. J Gastrointest Surg. 2015;19:1271-80.

25. Chia NH, Lai EC, Lau WY. Associating liver partition and portal vein ligation for a patient with hepatocellular carcinoma with a background of hepatitis B related fibrotic liver. Int J Surg Case Rep. 2014;5:1077-81.

26. Shindoh J, Truty MJ, Aloia TA, Curley SA, Zimmitti G, Huang SY, Mahvash A, Gupta S, Wallace MJ, Vauthey JN. Kinetic growth rate after portal vein embolization predicts posthepatectomy outcomes: toward zero liver-related mortality in patients with colorectal liver metastases and small future liver remnant. J Am Coll Surg. 2013;216:201-9.

27. Almau Trenard HM, Moulin LE, Padin JM, Stringa P, Gondolesi GE, Barros Schelotto P. Development of an experimental model of portal vein ligation associated with parenchymal transection (ALPPS) in rats. Cir Esp. 2014;92:676-81.

28. Croome KP, Mao SA, Glorioso JM, Krishna M, Nyberg SL, Nagorney DM. Characterization of a porcine model for associating liver partition and portal vein ligation for a staged hepatectomy. HPB (Oxford). 2015;17:1130-6.

29. Schlegel A, Lesurtel M, Melloul E, Limani P, Tschuor C, Graf R, Humar B, Clavien PA. ALPPS: from human to mice highlighting accelerated and novel mechanisms of liver regeneration. Ann Surg. 2014;260:839-46. discussion 846-837

30. Alvarez FA, Ardiles V, Sanchez Claria R, Pekolj J, de Santibanes E. Associating liver partition and portal vein ligation for staged hepatectomy (ALPPS): tips and tricks. J Gastrointest Surg. 2013;17:814-21.

31. Shindoh J, Vauthey JN, Zimmitti G, Curley SA, Huang SY, Mahvash A, Gupta S, Wallace MJ, Aloia TA. Analysis of the efficacy of portal vein embolization for patients with extensive liver malignancy and very low future liver remnant volume including a comparison to the ALPPS approach. J Am Coll Surg. 2013;217:126-33.

32. Robles R, Parrilla P, Lopez-Conesa A, Brusadin R, de la Pena J, Fuster M, Garcia-Lopez JA, Hernandez E. Tourniquet modification of the associating liver partition and portal ligation for staged hepatectomy procedure. Br J Surg. 2014;101:1129-34. discussion 1134

33. Fukami $Y$, Kurumiya $Y$, Kobayashi S. Associating liver partition and portal vein ligation for staged hepatectomy (ALPPS): an analysis of tumor activity. Updat Surg. 2014;66:223-5.

34. Truant S, Scatton O, Dokmak S, Regimbeau JM, Lucidi V, Laurent A, Gauzolino R, Castro Benitez C, Pequignot A, Donckier V, et al. Associating liver partition and portal vein ligation for staged hepatectomy (ALPPS): impact of the inter-stages course on morbi-mortality and implications for management. Eur J Surg Oncol. 2015;41:674-82.

35. Allard MA, Adam R, Bucur PO, Termos S, Cunha AS, Bismuth H, Castaing D, Vibert E. Posthepatectomy portal vein pressure predicts liver failure and mortality after major liver resection on noncirrhotic liver. Ann Surg. 2013; 258:822-9. discussion 829-830

36. Sakuhara Y, Abo D, Hasegawa Y, Shimizu T, Kamiyama T, Hirano S, Fukumori D, Kawamura T, Ito YM, Tha KK, et al. Preoperative percutaneous transhepatic portal vein embolization with ethanol injection. AJR Am J Roentgenol. 2012;198:914-22.

37. Yokoyama $Y$, Nagino M, Nimura $Y$. Mechanisms of hepatic regeneration following portal vein embolization and partial hepatectomy: a review. World J Surg. 2007;31:367-74.

38. Vicente E, Quijano Y, lelpo B, Duran H, Diaz E, Fabra I, Olivares S, Prestera A, Caruso R. Is "small for size syndrome" a relatively new complication after the ALPPS procedure? Updat Surg. 2015;67:273.

\section{Submit your next manuscript to BioMed Central and we will help you at every step:}

- We accept pre-submission inquiries

- Our selector tool helps you to find the most relevant journal

- We provide round the clock customer support

- Convenient online submission

- Thorough peer review

- Inclusion in PubMed and all major indexing services

- Maximum visibility for your research

Submit your manuscript at www.biomedcentral.com/submit
Biomed Central 